\title{
Nova etapa da RBMFC
}

New stage of the RBMFC

\author{
Nueva etapa de la RBMFC \\ Marcelo Marcos Piva Demarzo', Leonardo Cançado Monteiro Savassi², \\ David Matos Milhomens ${ }^{3}$, Gustavo Diniz Ferreira Gusso ${ }^{4}$
}

Wesse primeiro número de 2011, comemoramos uma nova etapa da Revista Brasileira etapa" compreende algumas mudanças importantes que vinham sendo gestadas nos últimos anos e que foram efetivamente implantadas neste ano: uma renovação da Política Editorial e, principalmente, o lançamento do portal virtual da Revista (www.rbmfc.org.br).

Todas essas mudanças, que detalharemos um pouco mais a seguir, visam basicamente melhorar a qualidade editorial e o alcance da RBMFC, pensando sempre nos seus principais protagonistas: leitores, autores e revisores de artigos. O objetivo da RBMFC continua o mesmo desde sua criação em 2004: ser veículo de divulgação do conhecimento científico produzido nacional e internacionalmente na área da Medicina de Família e Comunidade (MFC) e da Atenção Primária à Saúde (APS), incluindo todos os seus aspectos, de forma interdisciplinar: prática clínica, formação profissional, organização dos serviços e políticas públicas de saúde.

Quanto às inovações da Política Editorial, podemos destacar a criação de novas Seções na Revista, que visam ampliar as possibilidades de submissão para os autores para além das já tradicionais, tornando potencialmente mais interessante e dinâmica a leitura da RBMFC. Podemos citar alguns exemplos:

As seções Debate e Perspectiva têm a ideia de promover um espaço permanente para as opiniões qualificadas de nossos leitores e autores frente a temas atuais da MFC e APS. Visam também estimular a discussão e "oxigenar" controvérsias sobre aspectos relevantes dessas áreas do conhecimento. Nesta edição, estamos inaugurando um espaço permanente de debate intitulado "A APS que Queremos", inicialmente com alguns textos encomendados ${ }^{1-5}$. O objetivo é fomentar a discussão aberta, colaborativa e ética sobre um tema extremamente atual; e, nesse sentido, estamos esperançosos de que novos autores nos enviarão novas contribuições com diferentes opiniões e pontos-de-vista. Propostas de novos assuntos ou temas para debate também são bem-vindas.

A seção Casos Clínicos visa estimular a publicação das experiências clínicas singulares que envolvem o trabalho do médico de família e dos profissionais da APS. Tem o objetivo também de estimular o relato de casos que explorem os componentes do Método Clínico Centrado na Pessoa, ferramenta fundamental para a abordagem clínica na MFC e APS. Nesta edição, inau-

\footnotetext{
${ }^{1}$ Editor da Revista Brasileira de Medicina de Família e Comunidade (RBMFC). Docente do Departamento de Medicina Preventiva da Escola Paulista de Medicina da Universidade Federal de São Paulo (UNIFESP). E-mail: demarzo@unifesp.br

${ }^{2}$ Ex-editor da RBMFC. Docente do Setor de Medicina de Família e Comunidade do Curso de Medicina da Universidade Federal de Ouro Preto (UFOP). E-mail: leosavassi@gmail.com

${ }^{3}$ Bibliotecário. Secretário-executivo da RBMFC. E-mail: david@sbmfc.org.br

${ }^{4}$ Presidente da Sociedade Brasileira de Medicina de Família e Comunidade (SBMFC). Docente do Departamento de Clínica Médica da Faculdade de Medicina da Universidade de São Paulo (USP). E-mail: gusso.gustavo@gmail.com
} 
guramos essa seção com o interessante artigo de um colega de Portugal ${ }^{6}$, que nos relata sua experiência clínica e de coordenação de cuidados frente a uma pessoa em estágio terminal de vida.

A seção Memória inclui textos sobre profissionais ou fatos históricos que tiveram destacada contribuição para a MFC e a APS no Brasil e no mundo. Nesta edição, abrimos esse espaço com uma homenagem a Cecil Helman ${ }^{7}$, um dos ícones internacionais da Antropologia Médica, cujas ideias e textos exerceram e ainda exercem grande influência sobre a MFC e APS brasileiras.

Outras seções também foram criadas, mas ainda não inauguradas, como, por exemplo, a seção Atualização - que estimula a submissão de apresentações sucintas e comentadas de artigos de impacto publicados recentemente na área da MFC e APS - e a seção Espaço Aberto, que incentiva o envio de textos de reflexão pessoal com maior liberdade formal, incluindo linguagens poéticas ou literárias, ou ainda a publicação de entrevistas com depoimentos de pessoas ou profissionais, cujas histórias de vida ou realizações sejam relevantes para a MFC ou APS.

Nesta edição, trazemos ainda outros artigos originais e de revisão, como também um relato de experiência e resumos de trabalhos do $2^{\circ}$ Salão de Pesquisa em Medicina de Família e Comunidade do Rio Grande do Sul ${ }^{8}$. Assim, a RBMFC também tem se consolidado como veículo de comunicação científica das entidades de excelência em MFC, por meio das parcerias estabelecidas ao longo de sua existência.

Em relação à criação do nosso portal virtual, o mesmo possibilitará uma evolução sem precedentes para a RBMFC, permitindo, dentre diversos benefícios, maior facilidade de acesso ao conteúdo atual e pregresso da Revista, a implantação da submissão online (já em funcionamento) e a progressiva ampliação do número de artigos publicados por ano. Também está em andamento a implementação dos registros de DOI (Digital Object Identifier) para cada artigo publicado, que é um padrão internacional para identificação de documentos na rede de computadores, garantindo meios de acesso permanente aos links e facilitando a citação cruzada de artigos com outras publicações no Brasil e no mundo. Todos esses aspectos suportarão uma evolução quantitativa e qualitativa natural da RBMFC, que culminará, num futuro próximo, com a sua indexação nas grandes bases de dados nacionais e internacionais, como Lilacs, SciELO, Scopus e Medline.

Outros aspectos a se comemorar são o crescimento e a diversificação do número de revisores colaboradores da RBMFC (hoje, aproximadamente, 80 conselheiros e pareceristas com formação científica sólida), além do remodelamento da Revista impressa, mais moderna, repaginada, com nova capa, seguindo a tendência editorial dos mais conceituados Journals.

Desta maneira, a RBMFC continuará trazendo e publicando questões emergentes e fundamentais na área da MFC e APS, agora com um incremento considerável de qualidade e visibilidade, cumprindo seu papel de uma revista científica de relevância e espelhando uma prática de ciência plural, acessível e facilitadora na divulgação das contribuições intelectuais brasileiras e internacionais.

\section{Referências}

1. Silva FD. 40 horas na ESF? Rev bras med fam comunidade. 2011;6(18):15-6.

2. Lopes JMC. 40 horas na ESF? Rev bras med fam comunidade. 2011;6(18):17-8.

3. Anderson MIP, Rodrigues RD. Formação de especialistas em Medicina de Família e Comunidade no Brasil: dilemas e perspectivas. Rev bras med fam comunidade. 2011;6(18):19-20.

4. Rodrigues RD, Anderson MIP. Saúde da Família: uma estratégia necessária. Rev bras med fam comunidade. 2011;6(18):21-4.

5. Rodrigues RD. Estratégia Saúde da Família: bode expiatório? Rev bras med fam comunidade. 2011;6(18):25-6.

6. Cavadas LF. Articulação de cuidados pelo médico de Medicina Geral e Familiar: promovendo a melhoria da qualidade de vida em doente terminal. Rev bras med fam comunidade. 2011;6(18):63-70.

7. Oliveira FA. Em memória de Cecil Helman. Rev bras med fam comunidade. 2011;6(18):9-10.

8. Oliveira FA, Giugliani C, Kolling JHG. $2^{\circ}$ Salão de Pesquisa em Medicina de Família e Comunidade do Rio Grande do Sul. Rev bras med fam comunidade. 2011;6(18):71-2. 